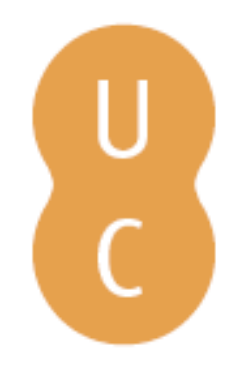

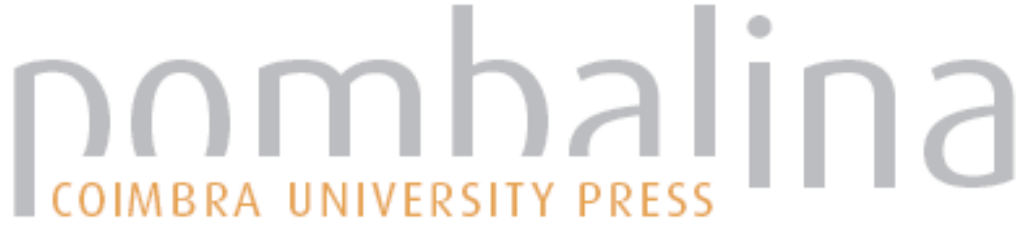

\section{Los encuentros geográficos, una oportunidad de compartir algo más que Geografía}

Autor(es): $\quad$ Villar Castro, Julio; Alonso Santos, José Luis

Publicado por: Imprensa da Universidade de Coimbra

URL

persistente: URI:http://hdl.handle.net/10316.2/43473

DOI: $\quad$ DOl:https://doi.org/10.14195/978-989-26-1343-7_3

Accessed : $\quad$ 26-Apr-2023 03:21:19

A navegação consulta e descarregamento dos títulos inseridos nas Bibliotecas Digitais UC Digitalis, UC Pombalina e UC Impactum, pressupõem a aceitação plena e sem reservas dos Termos e Condições de Uso destas Bibliotecas Digitais, disponíveis em https://digitalis.uc.pt/pt-pt/termos.

Conforme exposto nos referidos Termos e Condições de Uso, o descarregamento de títulos de acesso restrito requer uma licença válida de autorização devendo o utilizador aceder ao(s) documento(s) a partir de um endereço de IP da instituição detentora da supramencionada licença.

Ao utilizador é apenas permitido o descarregamento para uso pessoal, pelo que o emprego do(s) título(s) descarregado(s) para outro fim, designadamente comercial, carece de autorização do respetivo autor ou editor da obra.

Na medida em que todas as obras da UC Digitalis se encontram protegidas pelo Código do Direito de Autor e Direitos Conexos e demais legislação aplicável, toda a cópia, parcial ou total, deste documento, nos casos em que é legalmente admitida, deverá conter ou fazer-se acompanhar por este aviso. 


\section{FERNANDA CRAVIDÃO}

\section{IÚCIO CUNHA}

PAULA SANTANA

\section{NORBERTOSANTOS}

(ORG.)

\section{ESPAÇOS E TEMPOS EM GEOGRAFIA}

HOMENAGEM A ANTÓNIO GAMA

IMPRENISA DÁ UNIVERSIDADE DE COIMBRA COIMBRA UNIVERSITY PRESS

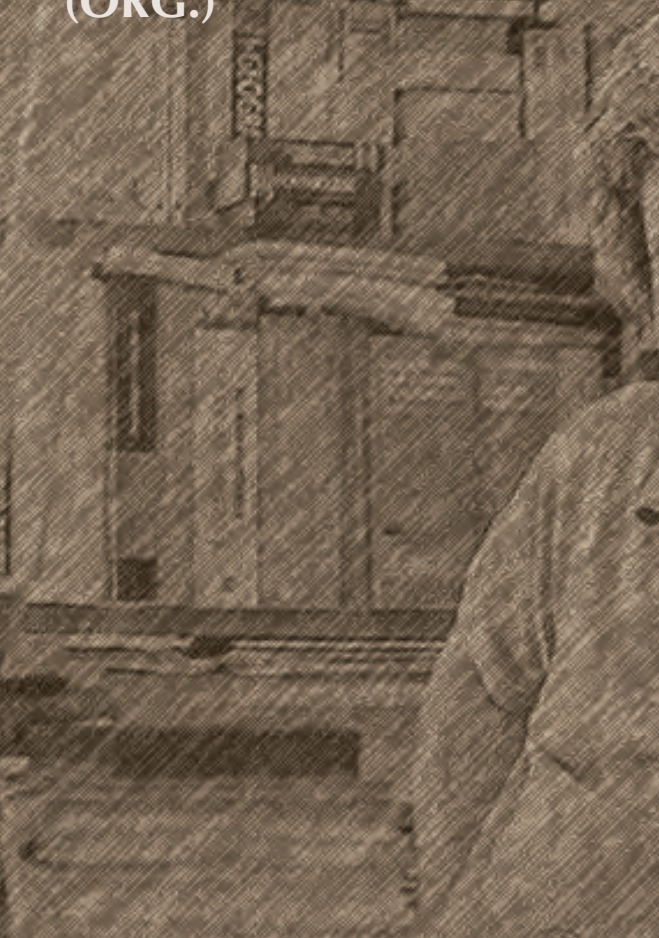




\title{
LOS ENCUENTROS GEOGRÁFICOS, UNA OPORTUNIDAD DE COMPARTIR \\ ALGO MÁs QUE GEOGRAFía
}

\author{
Julio Villar Castro/vilcas@usal.es \\ José Luis Alonso Santos/jlalonso@usal.es \\ Departamento de Geografia \\ Universidad de Salamanca
}

\section{Primera cita}

En los primeros días de mayo de 1979 se inician en Salamanca los Coloquios Ibéricos de Geografía, en cuya gestación tuvieron bastante que ver dos preclaros geógrafos con vocación iberista: Ángel Cabo y Orlando Ribeiro (†). Por aquel entonces, los autores del presente artículo eran unos jovenzuelos licenciados que habían conseguido colarse en el departamento salmantino como profesores ayudantes, aprovechando el boom de estudiantado universitario, la popularización de la universidad (hoy la llaman democratización, pero ya, ya) y la consiguiente demanda de profesores.

Aquella oportunidad de contactar con un significativo número de colegas de vocación ejercientes en todo el territorio portugués, creo, fue una agradable/inolvidable experiencia, al menos para nosotros. Pero si interesante era conocer qué geografía hacían nuestros vecinos, mucho más el encuentro sirvió para derribar barreras construidas con recelos y prejuicios a lo largo de siglos de ignorancia mutua amasados con lenguas diferentes, que servían de pretexto para la incomunicación, especialmente por nuestra parte. 
¡Cuántas experiencias y recuerdos de aquellas cortas jornadas!

Para empezar y afortunadamente, debimos olvidarnos del servicio de traducción aunque contábamos con la presencia de un colega de facultad del departamento de portugués para resolver puntualmente algún malentendido. Cada interviniente lo hacía en su propia lengua aunque no faltaba algún portugués que hacía sus pinitos en portuñol y con qué agrado recuerdo a Orlando Ribeiro y Jorge Gaspar expresándose en correctísimo español y permitiéndose bromas lingüísticas como la simplicidad vocálica del español que todo lo resolvía con tan solo cinco vocales mientras los portugueses (y los miraba socarronamente) precisaban casi del doble. La experiencia inversa no existió, lo que suponía, no lo neguemos, un pequeño complejo de inferioridad por nuestra parte, que bien venía para recolocar nuestro ego. Ciertamente, pudimos percatarnos de que ellos nos comprendían mucho más que viceversa y esto se notaba al llegar la discusión que seguía a las exposiciones; intervenían espontáneamente tras una exposición en español pero nosotros, a la inversa, permanecíamos mudos o hacíamos preguntas de ampliación informativa. Resumiendo, los portugueses nos comprendían mucho más que nosotros a ellos.

¿Qué esfuerzos de atención para seguir, al menos a grandes rasgos, los temas que se exponían! Y, sin embargo, qué pocas intervenciones al respecto! Estoy casi seguro que era por una extrańa mezcla de educación y vergüenza, aunque no sé si en este orden. Sí que recuerdo que a quien con más dificultad seguía (¿?) era a quien luego llegaría a ser entrańable amigo, António Gama. El enfoque filosófico que era tan de su gusto y el oscuro portugués en que se expresaba se nos quedó grabado desde el primer encuentro hasta el punto de que, en posteriores conversaciones, surgía con frecuencia esta expresión por nuestra parte: António, cada vez hablas mejor el portugués aplicada cuando constatábamos que el tiempo iba desgastando nuestras barreras lingüísticas y ganábamos en comprensión.

Como en cualquier encuentro de geógrafos no puede faltar la salida de campo allá nos fuimos a la Sierra, atravesando, claro está, por el paisaje rural más salmantino, la dehesa de encinas. Un pueblo típico, La Alberca, y una caminata 
para bajar desde el Portillo al convento a orillas del río Batuecas. Ah!, pero por aquel entonces el Portillo y el puente sobre el Batuecas solo estaban unidos por una pista de tierra. Por tanto, tras una breve explicación desde el balcón del puerto allá fuímonos todos ladera abajo atajando, a veces temerariamente, por trochas que ponían nuestras rodillas a prueba de todo. A medida que progresábamos iba asomando algún improperio y hasta exigencia de responsabilidades como la que profirió Pereira de Oliveira "quando estejamos a alcançar, eu vou perguntar ao professor Cabo como são os kilómetros em Espanha". Claro, es que un kilómetro por esa pendiente parecía equivalente a una milla aunque las piernas lo apreciasen como una legua y mucho me temo que la información inicial del profesor Cabo expresase la distancia en línea recta y seguramente proyectada, simplificación cartográfica que aquí era apreciada como una clara distorsión de la realidad por el sufrido profesor de Coímbra, cuya preferencia por la temática urbana experimentaba en este caso la apreciable diferencia del quehacer geográfico en ambientes tan contrastados.

Y acabó el Coloquio y cada artículo fue publicado en la lengua original, dando por supuesto que cualquiera, escrito, lo entendería perfectamente, aunque fuese ibérico del otro lado de la raya, que ya no frontera, al menos para los geógrafos concurrentes.

Ah!, ¿y de qué se habló en este I Coloquio? Pues de muy variados temas geográficos de ambos países, de información del otro, que es lo que más echábamos en falta. Estructurado en tres grandes temas de estudio, los trabajos versaron sobre el estado de la enseñanza y la investigación de la Geografía en ambos países, sobre sus estructuras agrarias y sobre las ciudades y su expansión reciente. Y así, de la mano de Carminda Cavaco, pudimos p.e. enterarnos de la importancia de la Reforma Agraria llevada a cabo por los gobiernos más izquierdistas de la Revolución de los Claveles, que tanta expectación (envidia romántica) había despertado en la España de la agonizante dictadura. Si bien buena parte de los trabajos presentados corresponden a geógrafos portugueses y españoles con dilatada experiencia, entre los más jóvenes aparece precisamente António Gama firmando, en colaboración con el Prof. Jorge Gaspar, el trabajo Perspectivas de la Geografía Humana en Portugal: Ensino, investigação 
e carreiras. Para saber más, vayan a la publicación ${ }^{1}$ los interesados; pero creo que lo más importante fue lo no publicado, las preguntas y opiniones sobre multitud de temas que interesaban a unos de los otros, pues nos desconocíamos. Especialmente los jóvenes, pero no solo.

Si en el campo del conocimiento geográfico fue mucho lo aprendido del "otro" país por los más de 200 participantes en este I Coloquio, para el Departamento de Salamanca y, más en concreto, para quienes escriben estas líneas se abría una fructífera relación académica que no hará más que ampliarse y diversificarse con el paso del tiempo. Y la relación muy pronto se trocó también en amistad personal con colegas de las universidades de Oporto, Coímbra y Lisboa. Y con António Gama pervivió por siempre.

Como secretario de aquel coloquio podría narrar muchas anécdotas, pero hubo una antes de iniciarse el mismo que se me quedó grabada respecto a una situación que bien pudo acabar al revés, y ahora aún me estaría arrepintiendo. Por lo visto, pero nosotros lo ignorábamos, la correspondencia en Portugal, al menos la internacional, pasaba siempre por Lisboa, lo que demoraba la recepción hasta unos límites insospechados. Bueno, pues de sopetón nos topamos con el problema (tarde de festivo, víspera del Coloquio): llegaban bastantes más portugueses que los que teníamos inscritos y todos estaban citados en el Colegio Mayor Hernán Cortés (edificio de nueva construcción), donde carecíamos de capacidad de acogida, y todos juraban haber enviado la preceptiva inscripción. Había que buscar otro alojamiento barato, y lo encontramos en el Seminario de Calatrava (vetusto edificio), pero ¡ay, las susceptibilidades!; orden alfabético, se nos ocurrió... y acertamos. Cuando tuve que comunicar a un grupo de portugueses que debían trasladarse a otro alojamiento (sin duda más oscuro y de peor aspecto) observé miradas llenas de desconfianza, pues pensaban que solo eran ellos los afectados. Con educada resignación me siguieron, pero tan solo su expresión hacia mí se tornó en amable y confiada cuando en los pasillos del Calatrava algunos reconocieron a otros geógrafos

${ }^{1}$ I Coloquio Ibérico de Geografía, Eds. Universidad de Salamanca. Cursos Extraordinarios, Salamanca, 1981, pp223 
españoles. Había caído la muralla del recelo secular; luego me enteraría qué conmemora la fiesta nacional portuguesa del 1 de diciembre y el monolito que da inicio a la Avenida da Liberdade en Lisboa (y también de cuál puede ser el origen de la segunda parte del dicho portugués "de Espanha, nem bom vento nem bom casamento").

\section{E virámo-nos de frente. Portugal se incorpora doblemente a nuestra vida e inquietud profesional}

El interés por el vecino, hasta entonces apenas conocido más allá de la esporádica visita a alguna villa fronteriza que a la par que satisfacía nuestro tímido exotismo nos surtía de productos tan simbólicos como café y vino de Oporto y, bueno, si acompañaba alguna mujer con la compra de los atoalhados, devino en un objetivo de interés mucho más allá de lo superficial anterior.

Nos adentramos en Portugal y descubrimos la costa, mucho más desarrollada de lo que suponía nuestra pobre imagen anterior. Y descubrimos la diferencia entre el Portugal del Norte y el del Sur, que se superponía a la contraposición costa-interior, y por aquellas endiabladas carreteras vimos el fuerte contraste de los nuevos flamantes autobuses de la Rodoviaria Nacional conviviendo con las camionetas y los carros de bueyes. Y también nos sorprendió la limpieza de las calles y la acogedora amabilidad de su gente, y la presencia más que anecdótica de una población negra, y de las nuevas y a veces presuntuosas (también inacabadas) casas levantadas por la nutrida población emigrante a la Europa Occidental, y las coloristas manifestaciones de religiosidad, y los peregrinos que bajo un sol de justicia en interminables filas por el borde de la calzada se dirigían a Fátima, sobre todo en los primeros días de agosto, y tantas otras cosas que luego nuestra cabeza se empeñaba en ordenar y explicar desde nuestra condicionada mirada geográfico-histórica; pero que solo tras conversar con alguno de nuestros colegas portugueses conseguíamos encajar. Así, nos asombramos ante el gigantesco esfuerzo que suponía la generosa acogida del millón de retornados en una sociedad que se había visto obligada a emigrar a 
la Europa rica, del efecto demostración de los emigrantes, especialmente nordestinos, de la diferente religiosidad del norte y sur, también observable en las tendencias políticas, de la influencia inglesa, del respeto al otro, de los judíos... y del bacalhau, seco, por supuesto, como inequívoco identificador nacional, mucho más que el fado o el galo colorista

Como nuestros colegas de Coímbra tomaron como tema de interés la franja fronteriza y allí hacían sus acampadas con alumnos, alguna vez nos invitaban y, aprovechando el fin de semana, aceptábamos el convite y hasta allá nos íbamos, como sucedió a mediados de los ochenta en la ribera del Erjas, inmediato a las termas de Monfortinho. Y cómo disfrutamos de las agradables veladas nocturnas con toda la tropa en torno al fuego y sus canciones, especialmente porque allí aprendimos (?) la tonada llena de connotaciones (y no solo para ellos) de la famosa canción de Zeca Afonso, Grândola, que con tanta devoción/sentimiento interpretaban; también algún fado de Coímbra ${ }^{2}$, bien diferente del lisboeta tanto por su temática como por su interpretación, que tan geográfico resultaba pues hablaba del curso del Mondego, desde su nacimiento a su final, en Figueira da Foz, tras pasar por la estudiantil Coímbra. Interesados por mostrarnos aspectos interesantes del entorno, allá nos acercaron hasta Idanha-a-Nova y a la bella atalaya de Penha Garcia o la impresionante villa de Monsanto. Por cierto, la tarde que llegamos a Alcafozes (Idanha) coincidió con una tourada en la plaza en un espacio acotado por carros, remolques, etc. y un locutor animando a la gente a jugar con el torito. Lo curioso fue que al descender de nuestros automóviles, con matrícula espańola, nos sorprendió oír por los altavoces algo así como "acabam de chegar uns carros com espanhóis..." y que desde lo alto del improvisado escenario de autoridades éramos invitados a subir y disfrutar del espectáculo a la par que se nos instaba a una participación más directa, que amablemente declinamos y más cuando alguien, quizás presumiendo que nuestra negativa era debida a la mas bien escasa envergadura del morlaco, nos

\footnotetext{
${ }^{2}$ Nos referimos, claro está, a los conocidos Corre Mondego y Balada da despedida, que muchos ańos después reconocí en la escultura colocada a la puerta de la Almedina con el estudiantil juego de volúmenes de guitarra y joven mujer.
} 
informaba que tenían otros toros con los cuernos más largos que el que estábamos viendo en el ruedo. No recordamos cómo terminó aquello, pero desde luego ninguno optamos al título de maestro taurino.

De aquella también recordamos cómo estando en lo alto de la hoz del Erjas, mirando hacia España, un viejo lugareño, al percatarse del carácter mixto del grupo, exclamó, a modo de advertencia y dirigiéndose a António Gama y a Joáo Ferrão, "de Espanha nem bom vento nem bom casamento", pero su expresión pícara nos decía que no iba en serio y, para que no hubiese duda alguna, de inmediato pidió a sus compatriotas que nos tratasen bien, que él había trabajado al otro lado de la frontera y siempre habían sido buenos vecinos. Los recelos históricos ya solo servían para hacer brincadeiras.

Y Portugal perdió para nosotros el carácter de exotismo próximo para ser sustituido por el más normal de vecino a conocer, aunque estuviese ahí desde siempre. Empezó a ser un destino incorporado a nuestro tiempo libre de fines de semana, puentes y vacaciones; dependiendo del tiempo disponible íbamos alcanzando territorios más alejados. Bueno, no solo nosotros, los geógrafos; una parte significativa de la clase media salmantina transformó la vecina costa portuguesa en lugar de veraneo con Figueira da Foz a la cabeza, conocida acá por unos ańos como la playa de Salamanca. Y es que, aunque en línea recta la zona de Aveiro está más próxima, las deficiencias viarias del Portugal de aquellos años prolongaban el viaje hasta límites que hoy nos parecen inverosímiles, y la hoz del Vouga era uno de los trayectos que se llevaban la palma. Claro que, luego, tras nuestra pareja incorporación a la C.E. en 1985, las cosas cambiaron sustancialmente y la IP5 abrió todo el abanico costero hasta Espinho.

Así fue como nuestro territorio vital y profesional se fue haciendo ibérico. Las incursiones para conocer las variadas teselas del mosaico lusitano se hicieron cada vez más frecuentes y poco a poco íbamos conformando imágenes más amplias a nivel regional a la par que nos surgían preguntas que procurábamos responder en un intento, seguramente inacabado, de comprender el conjunto de un país que apenas superaba en extensión a nuestra comunidad autónoma, pero cuya complejidad sí que lo hacía con creces. Éramos vecinos 
$y$, sin embargo, cuantas diferencias en aspectos que no habíamos reparado/ sospechado. Vayan aquí algunos, a modo de ejemplo:

* El común río Duero era en Castilla-León eje vertebrador del territorio mientras en Portugal era un marcado foso divisorio entre regiones (Tras-os-Montes y Alto Douro, a un lado, y Beira Alta, al otro).

* Nuestra costa cántabro-atlántica estaba plagada de puertos naturales abrigados y con calado (también de tranquilas playas) y, sin embargo, no sucedía lo mismo en Portugal; y todo por culpa de un litoral rectilíneo fruto de una costa baja de acumulación, más parecida a la de nuestro Mediterráneo, pero batida por el abierto océano.

* El espacio rural portugués ofrecía muchas menos posibilidades a la agricultura y, sin embargo, estaba más intensamente habitado y explotado que en España.

* Las ciudades portuguesas recuerdan bastante el carácter discontinuo y espontáneo del poblamiento rural, mientras las españolas mantienen una clara separación con el vacío campo circundante y son bastante más compactas y desarrolladas en altura ${ }^{3}$.

* La percepción del tiempo es bien diferente en ambas sociedades. Mientras para el español es un bien escaso, para el portugués más parece un patrimonio a consumir, como el agua, el aire o el sol. ¿Existe la prisa en Portugal? ¿No será que el sustrato rural sigue siendo el gen dominante en la sociedad?

Poco a poco fuimos descubriendo la riqueza del territorio portugués. La franja rayana, prolífica en ciudades o villas abaluartadas, especialmente en el lado lusitano, añadía otros ingredientes propios de zonas alejadas, de traspaís

\footnotetext{
${ }^{3}$ Esta apreciación coincide con la que nos trasladó Gama de sus alumnos y que en forma de pregunta demanda explicación epor qué la ciudad española (entiéndase de Castilla-León, Extremadura...) se acaba de repente siendo sustituida por el campo vacío? La respuesta que se nos ocurrió es que la gestión urbanística es bien diferente en ambos países. Mientras en España la Ley del Suelo, desde 1956, obliga a cada ciudad a la redacción previa de planeamiento donde se distinga claramente entre el suelo no urbanizable y el urbano o urbanizable y, además, determine los usos autorizados en cada polígono en que se divide el territorio (explicitado en los planos), tras la aprobación de cada PGMOU (Planes Generales Municipales de Ordenación Urbana) sus determinaciones son de obligado cumplimiento para la autoridad municipal (única gestora); en Portugal, sin embargo, no ha existido esa legislación y los planes tienen más un carácter propositivo/indicativo que ejecutivo, reconociendo incluso derechos urbanísticos a la propiedad de cualquier parcela rústica.
} 
de frontera, y así encontrábamos dialectos de origen mixto (mirandés en el lado portugués y 'a fala' o lagarteiro en el español) y también una disimulada presencia judía de la que había que estar advertido o tardabas bastante tiempo en percibir. Esta última, recuerdo, me la desveló tempranamente Gama como respuesta a mis observaciones respecto a costumbres sociales captadas en dos oportunidades distintas en Rio Maior, Portalegre y Castelo de Vide en momentos, próximos ambos, a la Semana Santa. Varios ańos después, el museo judaico de Belmonte y su aún activa sinagoga pusieron en orden mis dispersas observaciones y me permitieron establecer relaciones entre elementos comunes a ambos lados.

En el Portugal costero, aunque la captación/comprensión precisó de varias visitas y algún asesoramiento, destacaríamos el territorio de la laguna de Aveiro y su amplio entorno. Confieso que no hemos encontrado ejemplo que mejor condense las multifacéticas relaciones hombre-medio para conformar este magnífico paisaje anfibio ${ }^{4}$, donde hasta la luz, especialmente la matutina, brinda tantas oportunidades a las más variadas sensibilidades. ¿Por qué no se tomará este espacio como aula de campo de geografía, y también de pintura?

Y para finalizar con estas evocaciones al vecino incorporado a nuestro círculo de amistad, una de carácter histórico-cultural que involucra no solo a ambos países sino que invoca al gran imperio ultramarino lusitano y que es muy poco conocida, creemos, en el conjunto ibérico. Nos referimos al culto del Espíritu Santo, que hunde sus raíces en la Edad Media (o quizás mucho más atrás, en el culto a Ceres) y entra, al parecer, en Portugal de la mano de la bien conocida Isabel de Aragón (a Rainha Santa), desposada con el rey Don

\footnotetext{
${ }^{4}$ No es este artículo lugar para justificar el aserto pero, cuando menos, y de manera solo enunciativa, apuntamos las actividades propiamente marinas (puerto, astilleros, pesca), las de laguna-marisma (pescadores de anguilas, cangrejos y bivalvos de marea, los salineros, los secaderos de bacalao y los recolectores de junco moliço) y las de unos agricultores que han debido construirse hasta el suelo vegetal y que constituyen la seña de identidad de este paisaje a caballo entre los ambientes acuático y terrestre, los moliceiros. Y por si faltaba algún elemento más, en las inmediaciones tenemos el magnífico ejemplo industrial y urbanístico filantrópico de la cerámica de Vista Alegre. Y además, la compleja red de canales, las exclusas... y los rudimentarios barcos de blanca vela trapezoidal y coloristas ilustraciones naif, que son la enseña de este territorio, los barcos moliceiros, antańo siempre presentes y hoy casi condenados al rincón del olvido.
} 
Dinis I, a finales del siglo XIII y residente en los últimos años de su vida en el monasterio de Sta. Clara, en Coímbra. Nos topamos con este culto visitando las Azores y contemplando los abundantes y coloristas Impérios do Espírito Santo, sin que en aquel entonces pasaran para nosotros más allá del exotismo. Pero varios ańos después, al recorrer la singular ciudad de Tomar, un cartel publicitario de la fiesta dos tabuleiros con la llamativa corona del E.S. removió los recuerdos y se interesó por la relación. Unas pocas pesquisas y las piezas se unieron: Roma (?) - Aragón (Rainha Santa) - Portugal - Tomar (templarios) Azores - Brasil - Canadá y EE.UU.... una práctica de hermandad semi-religiosa, casi desaparecida en sus territorios de origen, que ahora pervive especialmente en lo que fueron posesiones ultramarinas portuguesas y es uno de los símbolos de identidad azoreanos.

A las vivencias personales hasta aquí mencionadas podríamos añadir, lógicamente, las profesionales, pero el estilo que hemos querido dar a este artículo las pone intencionadamente en penumbra. No obstante, al menos, mencionaremos las varias ocasiones en que asistimos como invitados a intervenir en varios Coloquios de Geografía en Coímbra, de los que en nuestra memoria quedó grabado especialmente el I, pues a duras penas conseguimos llegar por causa de un gigantesco temporal de nieve que bloqueó durante todo el día 5 de diciembre de 1996 todas las carreteras de la Beira Alta, desde el mismo paso fronterizo de Vilar Formoso; menos mal que nuestros reflejos actuaron rápido y conseguimos atravesar la $S^{a}$ de Gata antes de que el temporal cerrase también estos puertos, alcanzando Coímbra tras un largo rodeo por el sur (Castelo Branco). Y para finalizar, apuntaremos la primera tesis doctoral que aborda con perspectiva ibérica el impacto territorial del eje internacional más dinámico que liga Portugal con Europa Occidental 5 .

\footnotetext{
5 Sánchez Hernández, J. L. (1994). Ejes de desarrollo y articulación territorial: el ejemplo del eje Irún-Aveiro. Departamento de Geografía. Univ. Salamanca.
} 


\section{Incluimos al alumnado}

Hemos de reconocer que el primer paso para incorporar los respectivos territorios al campo de experiencias de nuestros futuros geógrafos correspondió a António Gama cuando, de improviso, se nos presentó en pleno verano del 84 en Salamanca con un pequeño grupo de alumnos. El sofocante calor lo mitigamos con una estancia campestre bajo las encinas de la dehesa y al borde del Tormes, que animaba al chapuzón. No recuerdo qué contenidos geográficos incorporamos al acerbo del alumnado visitante, pero sí que conseguimos cazar a algunos de nuestros alumnos del último curso y que ello transformó la visita en una primera convivencia internacional. De paso, se percataron de que los calendarios académicos de ambos países tenían sustantivas diferencias: mientras en España ya llevábamos algunas semanas de vacaciones veraniegas (de ahí que los ejemplares españoles que encontramos fuesen auténticos rezagados), el descanso académico en Portugal retrasaba su inicio, pero se prolongaba a septiembre.

Por aquel entonces ya teníamos en Salamanca a la Geografía como una especialidad de la licenciatura de Geografía e Historia ${ }^{6}$ y, por ello, nos planteábamos una mayor sistematización de la programación, sobre todo desde que en 1992 se implanta la licenciatura en Geografía. Entre otros acuerdos, en el departamento decidimos comprometernos a efectuar a lo largo de la carrera (4 años) una salida de campo de largo recorrido (extra-regional / internacional) y una visita a una gran metrópolis, en ambos casos con la pretensión de ampliar los horizontes del futuro titulado. Como era ya inveterada costumbre en el ambiente geográfico, para maximizar los objetivos de las salidas se recurría a los expertos colegas locales y, por ello, casi de inmediato, contemplamos al territorio portugués dentro de nuestro ámbito de interés. Los contactos estaban asegurados en prácticamente todas las regiones y en lo que a disponibilidad se refiere, jamás tuvimos problema alguno. Simultáneamente, nuestros colegas de la fraterna universidad de Coímbra hicieron lo mismo, al menos que sepamos,

\footnotetext{
${ }^{6}$ La primera promoción con la Especialidad de Geografía terminó en el curso 1977-78. La Licenciatura en Geografía se inicia en 1992-93.
} 
con nuestra región. Los futuros geógrafos salmantinos y conimbrigenses empezaron a tomar contacto no solo con el territorio sino con los profesores del otro país. Con el paso de los años, los programas Erasmus y el estímulo del Grupo Coímbra facilitaron las estancias de intercambio del alumnado entre ambas.

Las salidas largas, especialmente si se traspasaban las fronteras, tenían como destinatarios los alumnos de los últimos años de carrera. La primera vez que elegimos una gran urbe portuguesa, el honor correspondió a Lisboa y fue en 1988; pocos años después iríamos a Porto (1994) y volveríamos a Lisboa (2000) para evaluar los cambios urbanos tras la Expo. En todos los itinerarios el paso por Coímbra era obligado y, por supuesto, la pernocta en la Pensão Rívoli (Praça do Comércio) que siempre nos reservaba António como punto céntrico accesible a pie e inmediato a los frecuentados ambientes estudiantiles (visita obligada a la bellísima cafetería de Santa Cruz y la variada oferta del eje de ocio Arco de la Almedina-Quebra Costas), pues, como geógrafo humano, siempre consideraba de interés los ambientes vivos. Una de esas veces, al entrar con el autobús por el puente de Sta. Clara nos topamos con el desfile estudiantil de la Queima das Fitas y, claro, al día siguiente, la matutina explicación de la ciudad histórica no solo se demoró sino que tuvo un marcado déficit de atención. Un efecto colateral que António sabía disculpar.

De la primera visita a Lisboa, todos nuestros alumnos recordarán la mano levantada de João Ferrão con los dedos separados para explicar la trama esencial del plano de la ciudad a partir de la Baixa pombalina, y también que la metrópolis lisboeta, además de cosmopolita, tenía esos ambientes que el turista no visita, pero que forman parte de la urbe y que el geógrafo no debe olvidar; también aprendieron a valorar el problema de conexión entre ambos lados del estuario, y bastantes más aspectos que no tienen cabida aquí. En la visita posterior a la Expo ya pudimos apreciar la gran infraestructura del puente Vasco da Gama como solución al problema del paso del estuario, la reutilización de un espacio portuario marginal y el llamativo intercambiador de transporte; pero también la velada crítica subyacente al disfuncional diseño de Calatrava cuando, socarronamente, nos decían que "le habían encargado una estación y les había construido un apeadero". También pudimos contemplar in situ las 
consecuencias del desastroso incendio del Chiado y a la par extraer conclusiones respecto al erróneo mobiliario callejero que bloqueó la intervención de los bomberos. Para esta segunda ocasión tuvimos todo un equipo de expertos acompañantes: Diogo de Abreu, Jose R. Sirgado, Luis Moreno, Eduardo Brito, Júlia Ferreira y Paula Lema.

También un equipo de expertos implicados nos guió cuando visitamos Porto (1994) y su área metropolitana. Marília Silva, Júlia Lourenço y Madalena Magalhães nos recogieron en Peso da Régua y nos dieron cumplida explicación no sólo del viejo Porto y sus planes de recuperación de la ribera inmediata al puente de Luis I sino también de la nueva centralidad de Boa Vista y su relación con el nuevo puente, de la problemática industrial del área de Matosinhos, los problemas de competitividad del puerto de Leixóes y de tantos otros problemas abordados por el Plan Regional (PROZED).

En Coímbra, como ya hemos dicho, nuestro anfitrión y guía incansable fue siempre António, que también nos acompañaba en la mayoría de las ocasiones a Figueira, a Leiría, incluso a Aveiro, aunque ello le supusiera siempre la utilización del ferrocarril, pues, como bien sabemos los que le conocimos, no conducía automóvil y siempre sentía pudor a pedir a cualquiera que lo trasladase. Desde luego Comboios de Portugal ha perdido a uno de sus más fieles clientes. Cuando nos dirigíamos a Figueira, la parada en la atalaya de Montemor-o-Velho era obligada pues era el lugar ideal para apreciar la amplia planicie de campos de arroz que se extendía a ambos lados del Mondego y a la par, si había tiempo, en la pequeña ermita contemplar la curiosa imagen trigeneracional de Sta Ana-Virgen-Nińo. Ya después, en Figueira (la playa de Salamanca), el progresivo alejamiento de la costa provocado el espigón en la desembocadura en conjunción con la dinámica marítima dejaba en una curiosa posición a los apartamentos playeros de primera línea; también se nos quedó grabada la imagen del restaurante indú al que por exotismo nos llevó Gama y cuya especiada comida quedo para siempre fija en nuestra memoria.

Y ahora, recuperando el inicio de este apartado, referiremos las ocasiones en que actuamos de anfitriones y guías de los alumnos de Coímbra acompańados por Gama. Al igual que nosotros, pensando en los alumnos, buscábamos alojamientos 
accesibles a pie desde el centro y a los menguados bolsillos. No sé por qué vía, pues nosotros desconocíamos siquiera la oferta, António encontró por fin, tras tres o cuatro visitas, la residencia religiosa de los frailes Reparadores, inmediata al puente de Enrique Estevan, y desde entonces, por sus muy atractivos precios (tenían explicación tras la crisis vocacional religiosa y la abundante oferta de los semivacíos edificios del 'cinturón negro' de nuestra ciudad) siempre fue su campamento base; nuestra Pensão Rívoli, pero en Salamanca. Normalmente, el grupo llegaba un día de junio por la tarde, lo que permitía, tras la rápida descarga, una primera explicación de la ciudad histórica, aprovechando la magnífica posición de la propia Residencia, y un paseo a pie hasta el corazón de la misma (Pza. Mayor) para apreciar in situ los resultados de la recuperación del conjunto declarado Patrimonio de la Humanidad. Ahí, ya iniciado el crepúsculo, finalizaba la jornada reglada y tras unas breves informaciones de intendencia y oferta de ocio se iniciaba la fase individual de inmersión ambiental aleatoria, aunque los reencuentros nocturnos eran frecuentes. Tras una informal cena, el grupo profesoral y alumnos libremente asociados llegaba la hora de cumplir el sagrado ritual siempre demandado por António de "tomar um copo", habitualmente en el Camelot, quizás por el particular escenario de un antiguo refectorio convertido en estimulante ambiente de vicio (alcohólico).

De mañana, pero sin madrugar (la siempre comprensiva actitud de Gama), embarcábamos en el bus y, tras hacer un recorrido por las barriadas periféricas salmantinas enfilábamos hacia Zamora para pasear, por su eje comercial modernista, hasta la catedral y, desde la inmediata muralla aprovechar para explicar emplazamiento y configuración medieval con el arrabal de Olivares a nuestros pies. El autobús nos recogía abajo y, ya directamente por la comarca alistana, buscábamos uno de los pasos fronterizos ${ }^{7}$ hasta alcanzar la ciudad fronteriza,

\footnotetext{
7 Solo tras la supresión física de la frontera ibérica y el inmediato establecimiento de fáciles conexiones viarias, ansiadas por ambas partes, era factible la alternativa preferida por Gama: el paso por Moveros-Constantim, pues, para la temática fronteriza, esta puerta en medio de la penillanura y carente del más mínimo apoyo topográfico era una excelente muestra del carácter artificial de la misma a la par que explicaba la mutua influencia histórica y el origen mismo del segundo idioma reconocido en Portugal, el mirandés ( $o$ mirandês), perteneciente al grupo astur-leonés.
} 
económicamente 'virada' para España, de Miranda do Douro, donde la comida en el restaurante de Balbina devolvía a los alumnos a la cotidianidad.

Desde el mirador de la Sé y con el embalse de Miranda a los pies iniciábamos la última parte del itinerario, el del Duero internacional como gigantesco foso de separación y enormes posibilidades energéticas que precisaban del acuerdo entre países. Por tierras portuguesas y yendo paralelos a la abandonada línea férrea, que antaño llevaba a Porto, alcanzábamos el modesto embalse de Bemposta; pero antes, aprovechando un magnífico balcón antes de llegar a la presa, apreciábamos la faraónica obra de los bancales de Villarino que tanto recuerdan a los que aguas abajo son origen de los famosos oportos. Para sorpresa de todos, desde allí, pero arriba de todo (¡oh!), se ve perfectamente la gigantesca presa de Almendra y el seco cauce de confluencia Tormes-Duero; la sorpresa sirve de estímulo para intentar comprender el complejo aprovechamiento hidráulico y la funcionalidad de las turbinas reversibles de Villarino ${ }^{8}$. Tras la epatante vista de la gigantesca presa de Almendra nos encaminábamos sin demora hacia La Fuente de San Esteban donde nos esperaba con el automóvil cualquiera de nuestras mujeres para retornarnos a Salamanca. Un rápido hasta la vista / até já ponía fin al encuentro.

\section{El geógrafo y la persona en viaje por Salamanca}

Aquel primer contacto que fue el I Coloquio Ibérico de Geografía además de abrir nuestros horizontes geográficos al país vecino que en la práctica entraña sentirlo más próximo, con más frecuencia visitado y, a la postre más conocido y querido, abrió una fecunda relación académica con la geografía de Portugal que no hará más que fortalecerse y diversificarse con los años pero

\footnotetext{
${ }^{8}$ La primera vez, recuerdo que tras una mal comprendida explicación a la que contribuiría el 'portuñol' y el no encontrar anclaje en sus experiencias, António me hizo este comentario, que supongo inspirado por las dudas de sus alumnos y su faceta bromista, acompańado, sí, por una pícara sonrisa, pero solo tras el suspense final: "Olhe, Júlio, lá, em Portugal, a água vai sempre para abaixo, mas cá, em Espanha, da voltas e voltas... e depois?”.
} 
que, especialmente con A. Gama, nos llevó casi sin saber cómo ni por qué a un trato personal más allá del estrictamente académico. La relación adquiere naturaleza de amistad en la medida en que serán numerosas las visitas que António realiza a Salamanca en las que no es la actividad académica sino la amistad quien nos mueve. Si bien el tiempo transcurrido hace imprecisa la memoria no por ello es menos preciso el recuerdo de los encuentros casi siempre improvisados pero muy marcados por la imprevista presencia de António y la imprescindible visita a la Librería Cervantes con el consiguiente incremento de libros para su amplia y diversificada biblioteca personal en la que deben figurar no pocos títulos, no siempre de geografía, sino de filosofía, de sociología, de viajes, adquiridos en la recientemente desaparecida librería salmantina.

En ocasiones, los encuentros en Salamanca fueron muy breves ya que la razón de vernos podía ser la simple parada en la ida o la vuelta de uno de los viajes que le gustaba hacer al interior de la península o, también, porque algún colega de la Universidad de Coímbra tenía una actividad en nuestra Universidad y ello permitía a António visitarnos. En todos los casos, bien fuera el tiempo escaso o algo más relajado, ante un simple café en alguno de los múltiples bares que en la Plaza Mayor y su entorno tiene Salamanca, bien en la Facultad o bien en nuestras casas, la conversación se hacía intensa a la vez que amena, ya versara sobre la trivialidad diaria o se centrara en la propia geografía, la sociedad y la política del momento.

No siempre fue fácil seguir su relato, pues el hablar muy cerrado siempre le caracterizó, si bien nunca fue impedimento para seguir su sereno y atinado juicio crítico cuando se trataba de hablar del estado de la geografía a uno y otro lado de la Raya, o cuando el tema se deslizaba al transcurrir político de Portugal después de la Revolución de los Claveles o a la España postfranquista. Su amplia formación humanista y su atenta mirada a la situación internacional pronto le permitieron intuir los peligros que la globalización en marcha podía acarrear a las grandes mayorías sociales que, lamentablemente, en los años siguientes los hechos confirmarían con las sucesivas crisis económicas locales o internacionales... pero todas, como él muy bien había señalado, con fuertes costes sociales para las mayorías y el incremento de las desigualdades. Y es 
que en su manera de ser y pensar, lo inmediato, lo que vemos y está a la vista, podía ser la pantalla que ocultaba la razón última de las cosas y él gustaba de leer e intuir lo que la pantalla escondía. Fue Gama un gran lector, atento siempre a las nuevas ideas en el campo de las ciencias sociales y no sólo de la geografía. Pero sobre todo, sabía interpretar de forma magistral la realidad social y espacial local a la luz de las nuevas corrientes o teorías generales. En ocasiones se revelaba como un sońador, utópico, en pos de una imprecisa universalidad más social.

De la generosa humanidad de Gama habla también el hecho, tal vez anecdótico, pero sin duda revelador de su persona de que enredados en una larga conversación en presencia de dos nińas pequeñitas él de cuando en cuando, bien con servilletas de papel, bien con miga de pan les hacía, por supuesto sin dejar la conversación, figurillas, pajaritos, que hacían las delicias de las crías a la vez que cruzábamos miradas de complacencia sabiendo como sabíamos que no tenía hijos. Si el recuerdo es compañía, António siempre nos acompañará. 